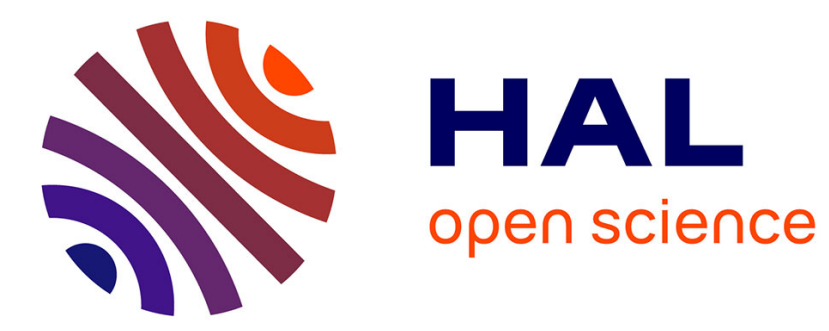

\title{
Comparison of instruments for geoelectrical soil mapping at the field scale
}

\author{
Michel Dabas, Erika Lück, Robin Gebbers, Horst Domsch
}

\section{To cite this version:}

Michel Dabas, Erika Lück, Robin Gebbers, Horst Domsch. Comparison of instruments for geoelectrical soil mapping at the field scale. Near Surface Geophysics, 2009, 7 (3), pp.179-190. 10.3997/18730604.2009011. hal-02922128

\section{HAL Id: hal-02922128 \\ https://hal.science/hal-02922128}

Submitted on 25 Aug 2020

HAL is a multi-disciplinary open access archive for the deposit and dissemination of scientific research documents, whether they are published or not. The documents may come from teaching and research institutions in France or abroad, or from public or private research centers.
L'archive ouverte pluridisciplinaire HAL, est destinée au dépôt et à la diffusion de documents scientifiques de niveau recherche, publiés ou non, émanant des établissements d'enseignement et de recherche français ou étrangers, des laboratoires publics ou privés. 


\title{
Comparison of instruments for geoelectrical soil mapping at the field scale
}

\author{
M. Dabas ${ }^{1)}$, E. Lück $^{2)}$, R. Gebbers ${ }^{3)}$, H. Domsch ${ }^{3)}$ \\ 1) Geocarta, France \\ ${ }^{2)}$ University of Potsdam, Institute of Geosciences \\ 3) Institute of Agricultural Engineering, ATB Potsdam-Bornim
}

\begin{abstract}
Precision Agriculture (PA) is a new application for sub-surface geophysics and can be classified in the field of environmental applications. The need of precise soil information with high spatial resolution is one of the many challenges of PA. Geoelectrical methods have shown their capability to detect spatial variation of important physico-chemical soil parameters in an efficient way. However, relationships between the electrical parameters (electrical conductivity or resistivity) and other soil properties are not always consistent over different fields. This can, to some extent, be due to the characteristics of instruments used for soil mapping. However, limited amount of research has addressed this issue. In this study, seven instruments for mobile mapping available on the market were investigated (ARP03, CM-138, EM38, EM38-DD, EM38-MK2, OhmMapper, Veris 3100). Instruments were employed under field conditions and results were compared with a high accuracy reference. Additional investigations were made concerning temperature drift and seasonal influences. Market differences between the instruments were found which have to be taken into account when geoelectrical surveys are planned or interpreted.
\end{abstract}

Keywords: Electrical resistivity, electrical conductivity, electromagnetic induction, direct current method, galvanic coupled resistivity method, capacitive coupled resistivity method, accuracy, depth of investigation, temperature drift, seasonal influences, ARP03, CM-138, Earth Resistivity Meter, EM38, EM38-DD, EM38-MK2, GeoTom, OhmMapper, Veris 3100.

\section{Introduction}

Precision Agriculture (PA) is a new domain of application for sub-surface geophysics. Geoelectrical mapping has proven to be useful in detecting soil spatial variations, which often can be related to soil properties relevant for plant growth. For instance, soil EC (ER) is linked to:

- soil salinity (Lesch, Corwin \& Robertson 2005, Triantafilis 2000),

- soil texture (Lück \& Eisenreich 2003, Lesch, Corwin \& Robertson 2005, Sudduth et al. 2005, Domsch \& Giebel 2004),

- cation exchange capacity (Sudduth et al. 2005),

- soil moisture (Bobert et al. 2003, Lück \& Eisenreich 2003, Sudduth et al. 2005, Reedy \& Scanlon 2003, Tarr et al. 2005),

- organic carbon (Lück \& Eisenreich 2003, Sudduth et al. 2005, Tarr et al. 2005),

- plant available P (Jung et al. 2005, Tarr et al. 2005),

- plant available K (Tarr et al. 2005),

- $\mathrm{pH}$ (Tarr et al. 2005),

- bulk density (Jung et al. 2005), 
- nitrate (Cockx et al. 2005, Korsaeth 2005),

- soil types (Anderson-Cook et al. 2002).

Whereas the influence of salinity normally plays a minor role under temperate conditions, clay content and water content are usually the most important factors causing spatial variations in EC maps (Schmidhalter, Zintel \& Neudecker 2003, de Jong et al. 1979, Kachanosky et al. 1988).

Based on these correlations, geolectrical maps can be used

- as an auxiliary variable to interpolate other soil properties obtained from sparse sampling by methods like regression, regression kriging or co-kriging,

- to derive management zones (King et al. 2005),

- to optimize soil survey by guided sampling (Kerry \& Oliver 2003),

- to explore soil-yield relationships (Anderson-Cook et al. 2002).

However, correlations between soil EC (ER) and other soil parameters are sometimes inconsistent when compared over different fields and landscapes (Tarr et al. 2005, Sudduth et al. 2005). This can be due several reasons:

- multiple influences on soil EC (ER) where sometimes one effect can mask others,

- human impact (e.g. fertilization, tillage, crop rotation),

- errors in measurements of the other soil parameters,

- errors in EC maps,

- inconsistency between depth and volume of soil samples and depth response of the geoelectrical instruments.

The last two reasons are related to the geoelectrical instrument. Accuracy of the instrument and its depth response may have a large influence on the applicability EC maps. However, there has been only a limited amount of research focused on comparing EC measurement results obtained from different near-surface geophysical methods (Allred, Ehsani, Saraswat 2006). The few studies reported in the literature were restricted to a small number of instruments (e.g. Sudduth et al. 2003) or very specific site conditions, not typical for agricultural soils (Allred, Ehsani, Saraswat 2006). Additionally, all of these studies neglected to use accurate geoelectrical measurements as a reference.

In order to gain a better understanding of the quality of EC (ER) maps, we have initiated a unique field test with seven commercially available instruments.

\section{Materials and Methods}

\section{Experimental design}

Measurements with the different geophysical instruments were carried out on a small field (described below) starting in summer 2003 during the fourth European Conference on Precision Agriculture. Afterwards, complementary investigations and repeated measurements were added.

Tests included seven instruments for mobile geoelectrical mapping: ARP03, CM-138, EM38, EM38-DD, EM38-MK2, OhmMapper, Veris 3100 (details are given in the instrument section below). The ARP, EM38DD and Veris 3100 were dragged by an ATV and georeferenced by dGPS. Due to practicability and/or to increase positioning accuracy, the other instruments were dragged by hand and located by tape or dGPS. 
Comparison of maps is a very difficult exercise. Lot of factors interfere, like the dimension of mesh, the type of mathematical functions used as interpolator or the way to handle duplicate data for example. Thus, in a first step we focused only on data that are as close as possible to the 'raw' data with a minimum positioning error. This could be accomplished best by working on a single transect. To establish a reference as a common basis for comparison, a transect was selected after initial mapping of the field with the EM38-DD. The transect of $158 \mathrm{~m}$ length was located at the western boarder within the field. It covers the full range of conductivities observed in the field and showed some marked structures. All mobile instruments were employed over the field and data were further extracted from this 2D set to match the geometry of the transect. Additionally two geoelectrical instruments (GeoTom, ERM, see below), operating in a stationary mode, were used to obtain reliable reference data. Soil sampling and consecutive laboratory analysis provided soil texture and actual water content.

The GeoTom was used as the main reference method. To test this reference, we used the ERM borehole probe to collect profiles of in-situ conductivities at 14 positions on the transect (Fig. 9). These data were compared with inverted GeoTom values. The idea behind this was that if inverted values were comparable with in-situ data, it could be assumed that surface measurements were accurate and could serve as a reference.

While we were not able to collect all data at the same date on one hand and we were concerned about stability of some instruments on the other hand, we considered time stability of the mapping results. Thus, we have investigated the influences of temperature and seasonal effects. To investigate the influence of air temperature on the EM38, the CM-138 and the OhmMapper, the instruments were exposed to varying temperatures at a fixed position while readings were taken every second. Seasonal effects in the field were examined by two surveys of the field with the EM38 and four soundings on the transect with the GeoTom. Mapping to field extent with the EM38 was carried out on a dense grid with point distances of $1 \mathrm{~m}$ along a profile and $2 \mathrm{~m}$ between profiles in summer 2003 and winter 2004. Repeated measurements with the GeoTom on the transect took place in summer 2003, winter 2004, winter 2005, and spring 2005.

Positioning accuracy can influence the quality of geoelectrical maps as well. Thus, working on the transect using a measuring tape was preferred and special care was take to detect and correct for positioning errors.

Maps were generated form surveys of the whole field with the ARP, CM-138, EM38, EM38-DD, and Veris 3100.

\section{Instruments}

The following geophysical instruments for continuous mobile mapping were tested:

- Two systems based on the galvanic coupled electrical resistivity technique (GCR): the ARP03 (Geocarta, France) and the Veris 3100 (Veris Technologies, USA) (Fig. 1). The rolling electrodes (coulters with spikes) of the ARP system are arranged in a trapezoid pattern. Current electrodes have a spacing of $1 \mathrm{~m}$; potential electrodes have spacing of $0.5,1$ and $2 \mathrm{~m}$. The Frequency is about $225 \mathrm{~Hz}$, voltage can be varied between 0 and $200 \mathrm{~V}$ depending on contact resistance conditions of the site. Veris 3100 works with two depths. The injected current is less than $100 \mathrm{~mA}$ at a frequency of about $150 \mathrm{~Hz}$. The six rolling electrodes (smooth coulters) are arranged in a line forming a Wenner array. For shallow measurements, separation distance of the electrodes (a) is about $24 \mathrm{~cm}$ and for deep measurements a is $72 \mathrm{~cm}$.

- Four systems based on electromagnetic induction (Fig. 2): the EM38 (Geonics Ltd., Canada) in vertical and horizontal dipole mode, the EM38DD (Geonics Ltd., Canada), 
the prototype of EM38-MK2 (Geonics Ltd, Canada) and the CM-138 (GF Instruments, Czech Republic). Beside the EM38-MK2, all of these instruments maintain a $1 \mathrm{~m}$ intercoil spacing and operate at $14.6 \mathrm{kHz}$. The EM38-DD consists of two EM38 attached together in order to have simultaneous measurements in vertical and horizontal mode. To avoid interference, one of the paired instruments of the EM38DD works at a slightly different frequency. The EM38-MK2 has three coils and works at higher frequencies (probably $40 \mathrm{kHz}$, but this was not confirmed by the manufacturer). Two coils are $1 \mathrm{~m}$ apart, the third is placed in the middle to achieve a spacing of $0.5 \mathrm{~m}$. The EM38-MK2 we used was a prototype especially designed for the Technical University of Munich. Currently, Geonics is planning to commercialize the EM38-MK2, release is scheduled for the end of 2007. The main differences between the CM-138 and the EM38, as claimed by Gf Instruments, are that the CM138 needs no manual calibrations and temperature stability is high.

- The OhmMapper (Geometrics Inc., USA), which is based on a capacitive coupling of line electrodes (Fig. 2). Two insulated coaxial cable sections of 2.5 and $5 \mathrm{~m}$ were realizing dipoles of 5 and $10 \mathrm{~m}$ length. The cables are forming one plate of a capacitor, the soil forms the other capacitor plate. Distances between the dipoles could be set arbitrarily. Lengths of $0.5,1.0,2,0,2.5,3.0$ and $4.0 \mathrm{~m}$ were chosen. Operating frequency is $16.5 \mathrm{kHz}$ and current is selected automatically.
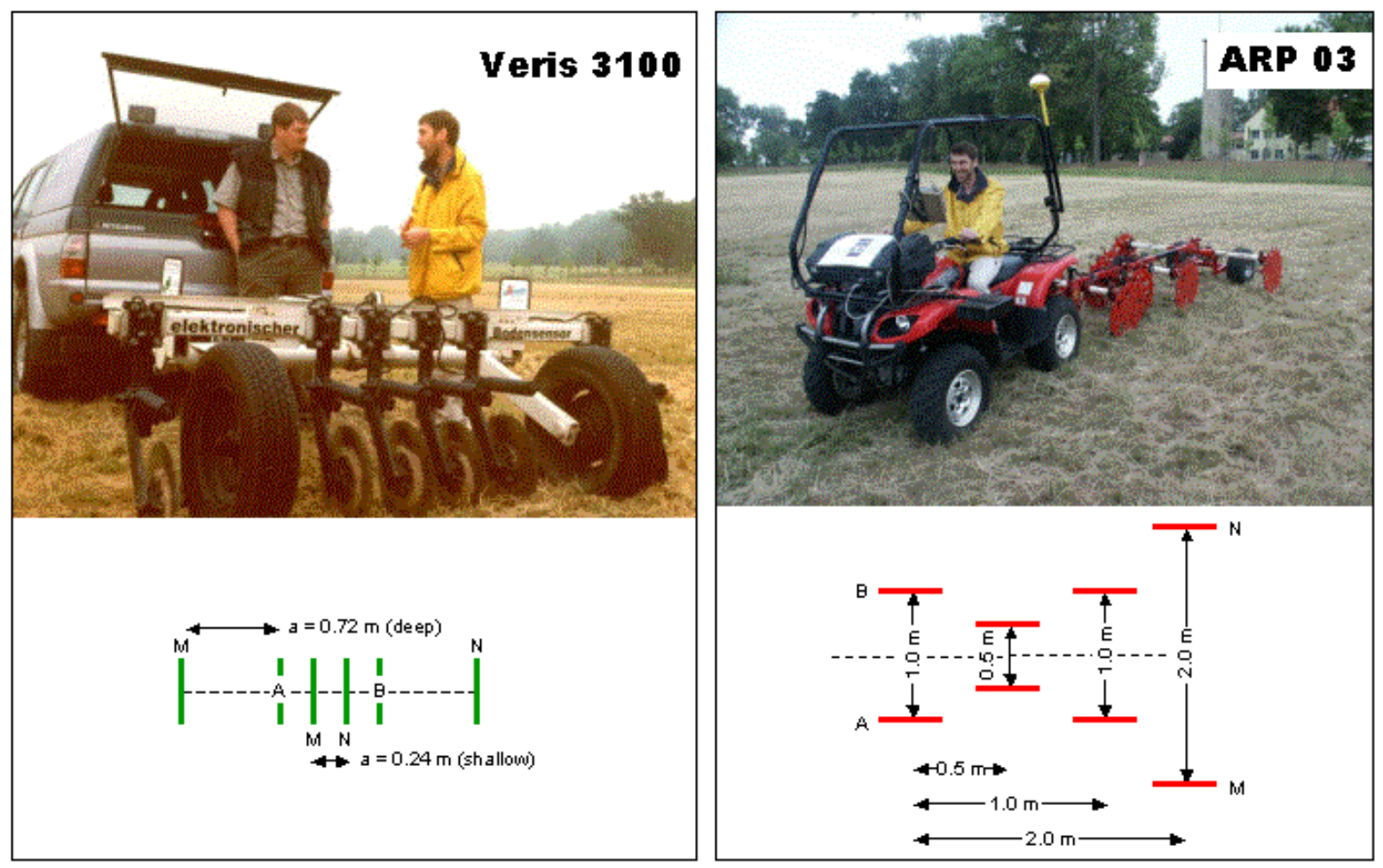

Fig. 1: Tested instruments: Veris 3100 (left) and ARP 03 (right) 

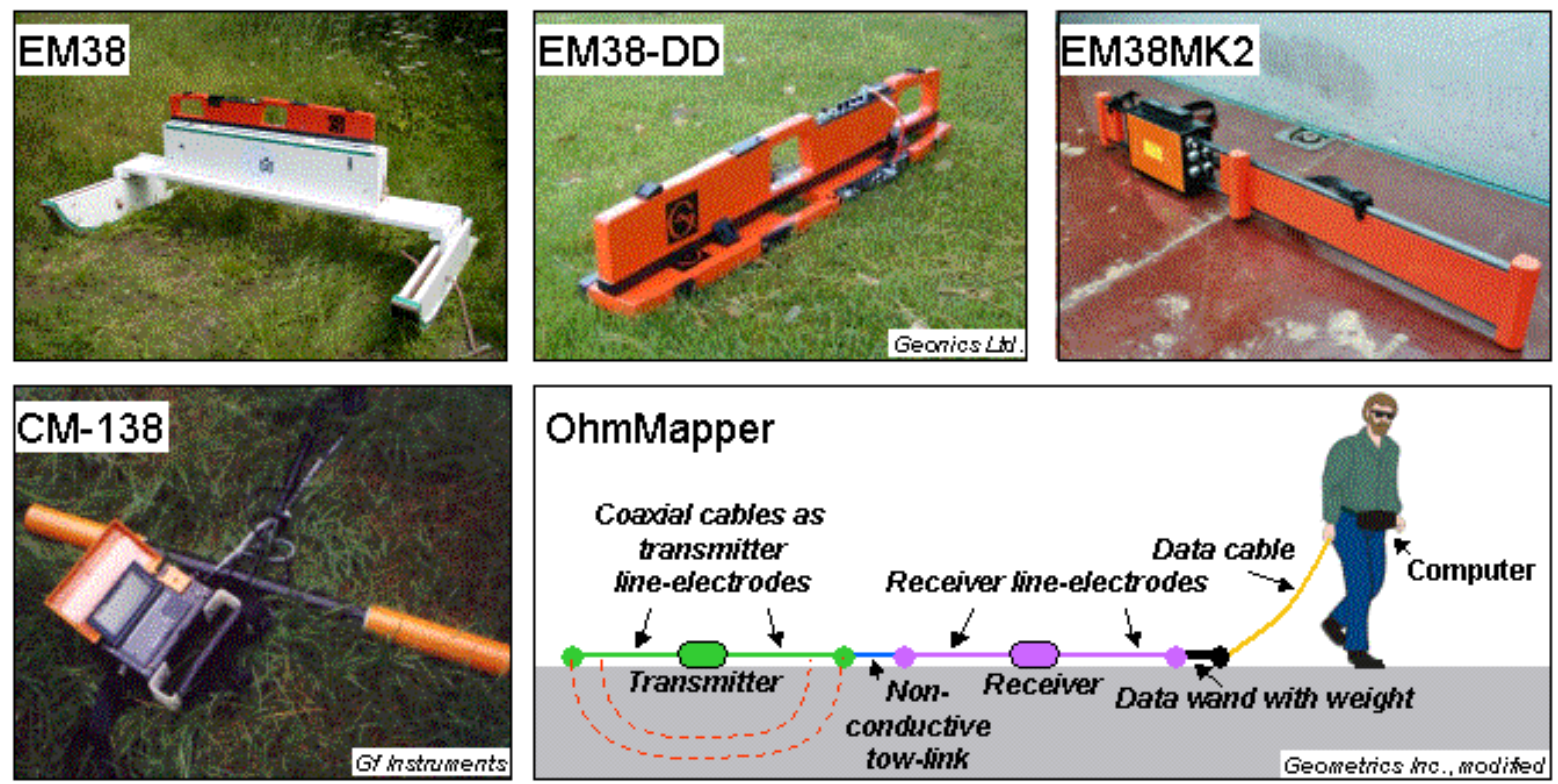

Fig. 2: Tested instruments: EMI instruments and the OhmMapper

Two instruments were used as references (Fig. 3):

- A multi-electrode switching system GeoTom 200/100 RES/IP (GeoLog, Germany) was used for depth sounding along the transect. Electrodes were switched in a Wenner configuration starting with electrode spacing ' $\mathrm{a}$ ' $=0.5 \mathrm{~m}$ and increasing stepwise up to ' $\mathrm{a}$ ' $=4 \mathrm{~m}$. This enables an investigation depth of 0 to $2 \mathrm{~m}$ approximately. Measurements were controlled by a software which restricted noise to a maximum of $1 \% \mathrm{CV}$. Thus, the GeoTom data are assumed to be the most accurate electrical surface data obtained over transect. Spatial resolution is the minimum distance between electrodes $(0.5 \mathrm{~m})$.

- For in-situ measurements, the direct push measurements ERM, Earth Resistivity Meter 14.01. was used (Eijkelkamp, The Netherlands). The four electrodes in the sensor tip are forming a Wenner-array with a spacing of ' $a$ ' $=20 \mathrm{~mm}$. This results in sensing approximately $80 \mathrm{~cm}^{3}$ of soil volume. The probe has to be operated manually up to $1 \mathrm{~m}$ depth with a vertical resolution of $5 \mathrm{~cm}$. 

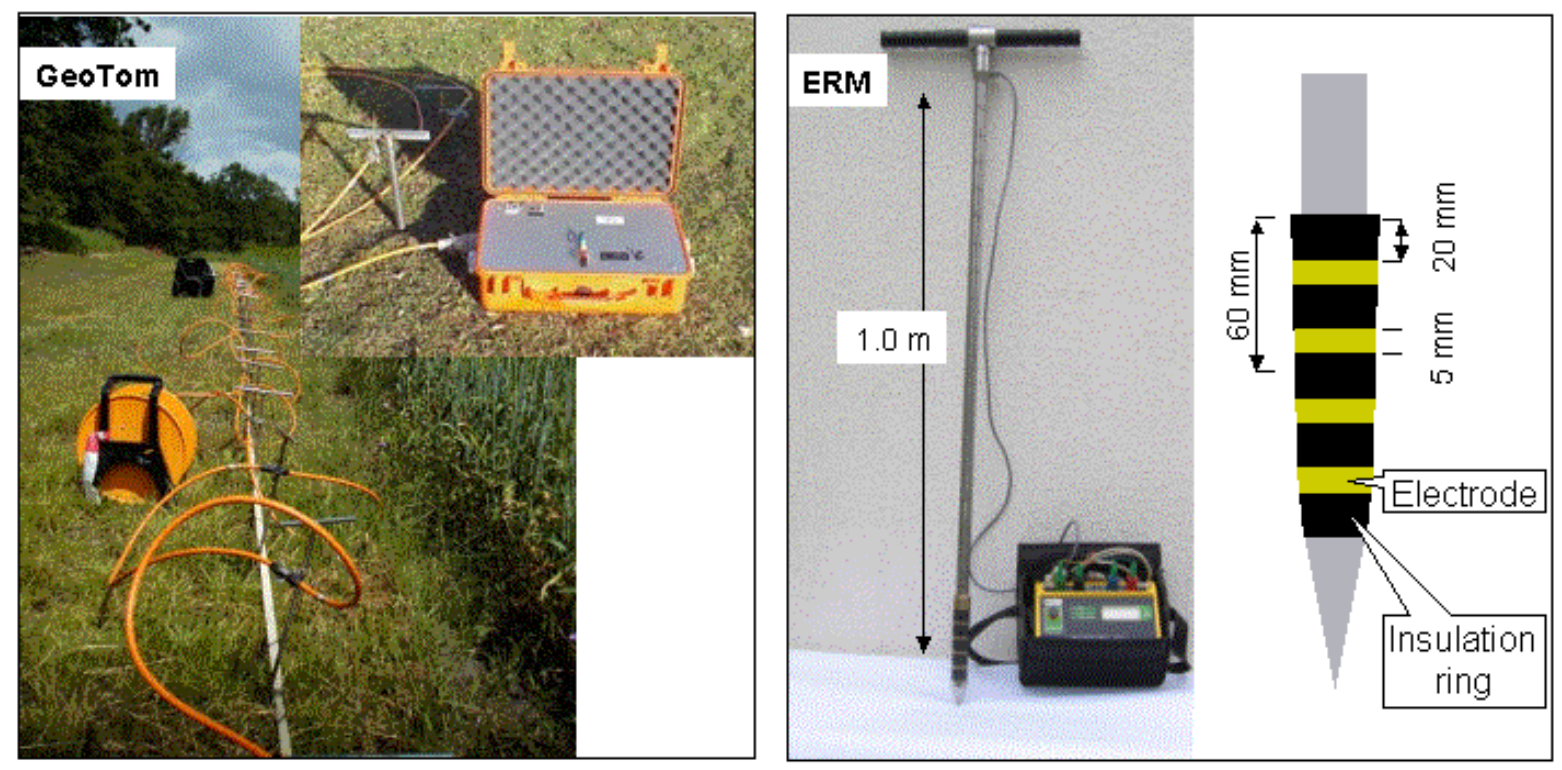

Fig. 3: Reference instruments: GeoTom multi-electrode array (left), ERM borehole probe (right)

\section{Description of the test site}

The test site is situated in Germany near Potsdam (Bornim), $30 \mathrm{~km}$ west of Berlin. It is a small field of $115 \mathrm{~m}$ by $160 \mathrm{~m}$ covered with grass. The landscape was formed by the last ice age. Soil texture of the test site is dominated by loamy sand. Texture analysis for soil samples up to $1 \mathrm{~m}$ depth yielded in a medium sand content of $75 \%$, silt content of $17.2 \%$ and a clay content of $7.8 \%$. The site has a history of intensive land use. After being an orchard of the royal court of Prussia, it belonged to an agricultural research station since 1927. In the last decades, the test site was not used for plant production. Two farm buildings were established and water pipes were laid through the field. About 10 years ago, the buildings were removed, the land was recultivated and set aside. Due to this history of land use, the soil is strongly compacted in parts of the site, we found rubble, and beside at least two pipelines in the underground, many other metal objects were present near the surface of the soil.

This site was chosen for its practicability as a location of a field day during the fourth European Conference on Precision Agriculture. Of course, it was not intended to be representative of some type of agricultural field. Nor its small size (1.8 ha), nor its long history, can guarantee the applicability of the results obtained for other field conditions. Nevertheless, we feel that most results obtained like sensitivity depth, conditions of operation, degree of autocorrelation between two periods of time, or crosscorrelation between instruments are valid whatever the type of soil encountered.

\section{Data analysis}

WGS84 geographical data from dGPS receivers were transformed using a UTM projection to obtain Cartesian coordinates (ellipsoid DHDN12/PD Bessel 1841, 7 Helmert parameters transformation). For data analysis on the transect, UTM coordinates were converted into local coordinates (transect position) by a simple two-parameter transformation.

For comparison of EC and ER measurements, ER data were converted to EC $(\mathrm{mS} / \mathrm{m})$. Crosscorrelations on the transect were computed with a script programmed in Matlab (Kendall's tau according to Siegel, 1985). Kendall's Tau $(\tau)$ rank coefficient of correlation 
was chosen because it can handle non-linear relationships (monotonous increasing/decreasing) and it is robust against outliers.

Because readings were not exactly co-located, we calculated $\tau$ for pairs of points within a specific distance (lag). For GPS georeferenced measurements, lag width was set to $2 \mathrm{~m}$, for tape measurements, lag width was set to $1 \mathrm{~m}$. Positions due to offset between GPS antenna and instrument or due to systematic GPS errors were corrected by shifting positions up to $2 \mathrm{~m}$ (shift was optimized by maximizing $\tau$ ). To derive a pseudosection of true electrical conductivities by inversion, multi-electrode data were processed with RES2DINV (GeoTomo software, Malaysia).

Grid maps of 4 by $4 \mathrm{~m}$ resolution were produced by using triangulation with linear interpolation (Surfer v8).

\section{Results and discussion}

\section{Time stability}

\section{Temperature drift of EMI instruments and the OhmMapper}

During the cooling up and cooling down of the EMI instruments EM38 and CM-138 considerable variations of apparent conductivities were observed. The temperature drift of $\sigma$ the EM38 was much lower than that of the CM-138, which deviated up to $50 \mathrm{mS} / \mathrm{m}$. Additional, the CM-138 showed jumps in conductivity values (Fig. 4). Because positions did not changed during this experiment, EC variations should be interpreted as instability of the EMI instruments. Probably drifts and erratic jumps in EC readings of EMI instruments cannot only be related to temperature but also to ambient noise from various electro-magnetic fields (McNeil 1980, Sudduth, Kitchen \& Drummond 2001).

Time series measured with the OhmMapper exhibited a small drift of up to $0.4 \mathrm{Ohm} \cdot \mathrm{m}$ over 0.5 hour. This drift was not dependent on the absolute level of resistivity. 

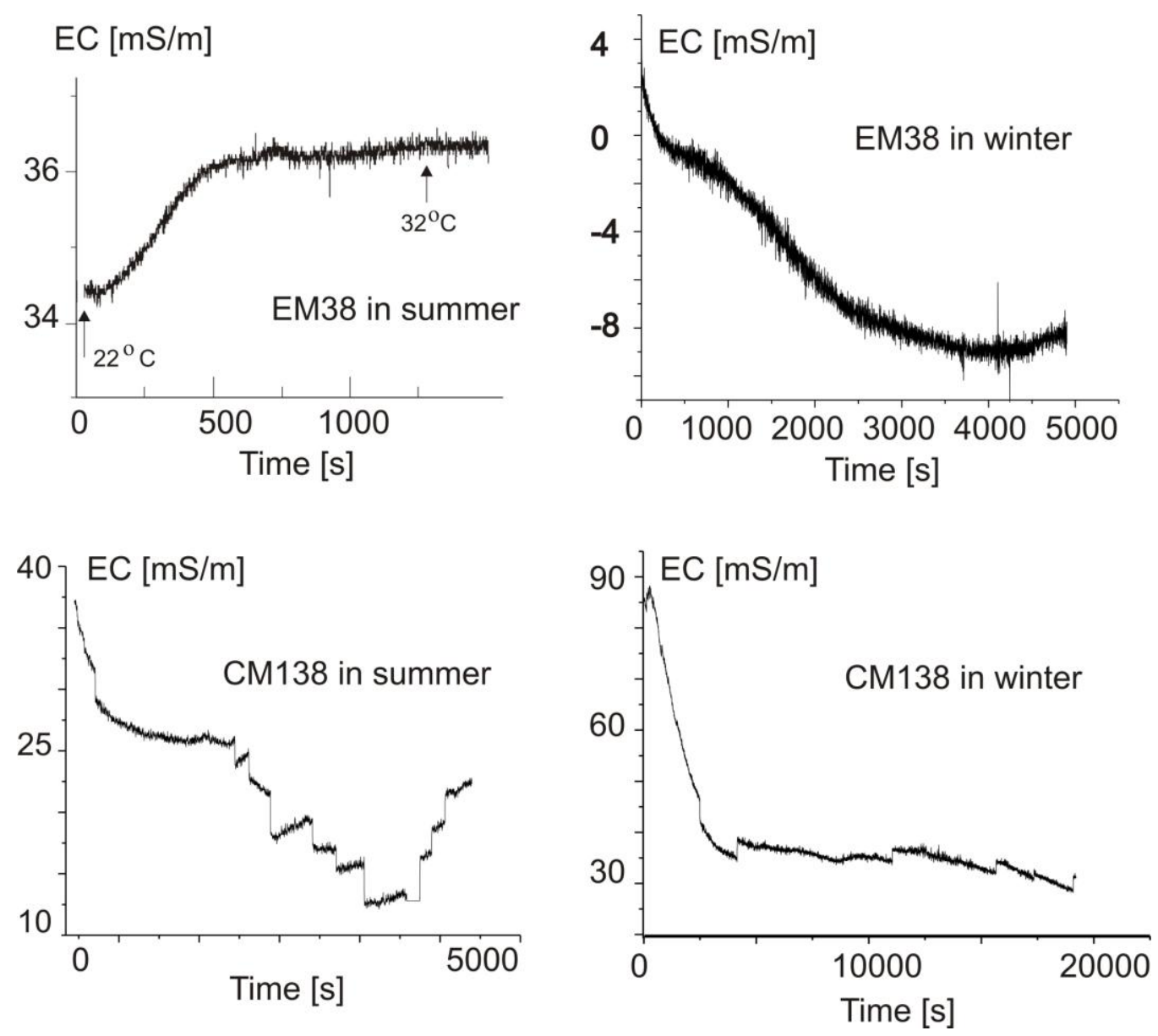

Fig. 4: Drift of electromagnetic measurements at a fixed position due to a change of air temperature (left column: warming up, right column: cooling down, upper row: EM38, lower row: CM-138)

\section{Stability of measurements over different seasons}

The spatial conductivity patterns were quite stable at the site. This was confirmed by repeated conductivity mapping during summer and winter with the EM38 and by repeated DCmeasurements with the GeoTom along transect.

Fig. 5 shows the comparison of two surveys using the EM38 in summer 2003 and winter $2003 / 2004$. A general decrease of winter conductivities of approximately $25 \%$ compared to summer conductivities was noticed (Fig. 4). Three factors can account for this difference: the thickness of the snow modified the above ground height of the instrument and consequently lowers the response (a $20 \mathrm{~cm}$ snow cover results in a $7 \%$ decrease in VCP or $33 \%$ in HCP mode), a bad calibration of the instrument with or without temperature drift or the temperature dependence of EC of the soil materials. It is not possible here to separate these three factors. 


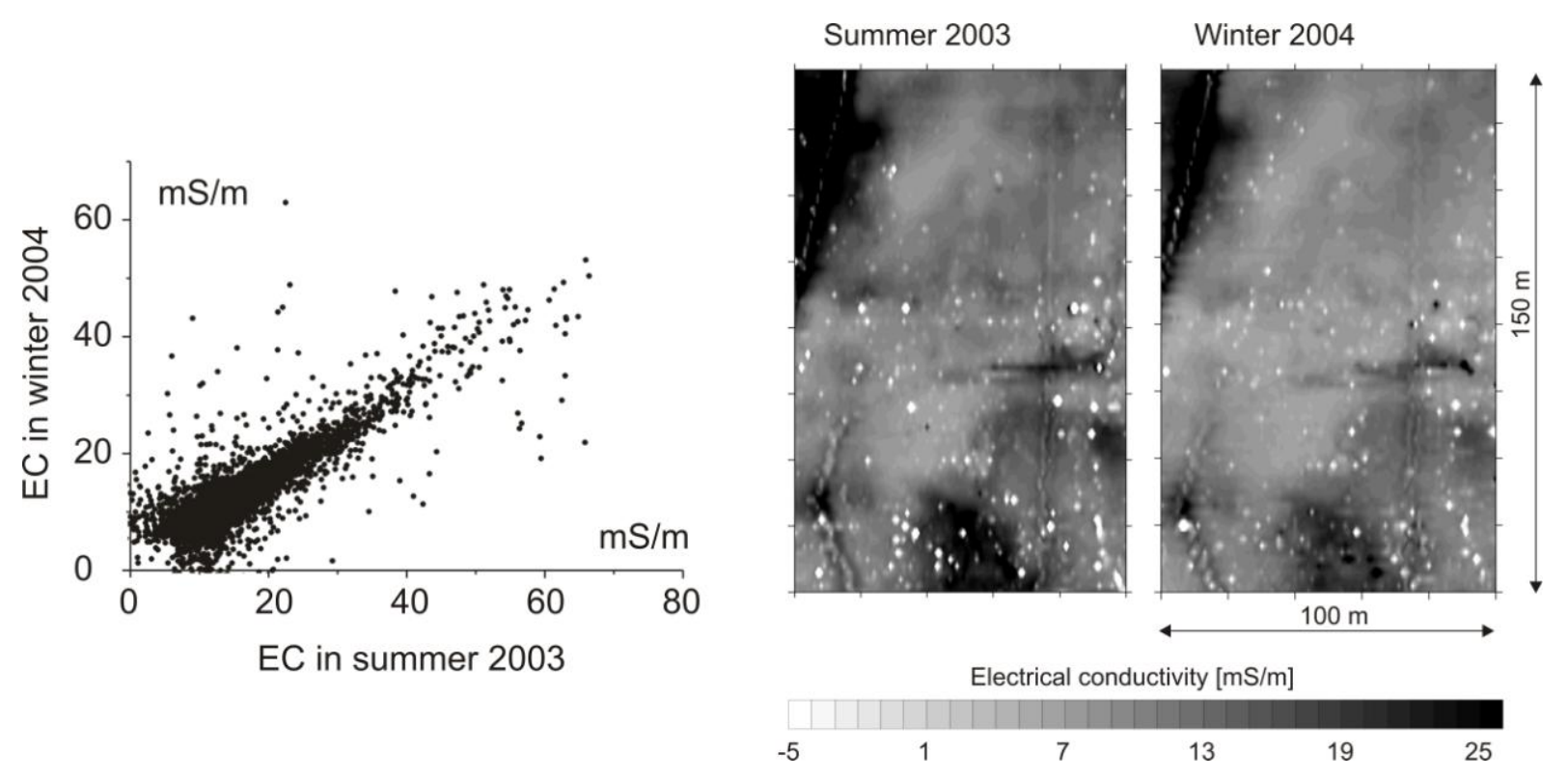

Fig. 5: Comparison between EC values measured with EM38 at two different dates (Left: scatter plot of values taken at the same locations; Right: conductivity maps, negative EC values (white dots) are caused by metal objects near the surface)

Pseudosections, derived from measurements with the GeoTom at four different dates are presented in Fig. 6. We can see a small variation in absolute values due to water content and soil temperature (Figure 6, left), but the imaged structures were nearly the same over time. In summer 2003 we observed values for soil moisture of $5.5 \%$ at the surface and $9.7 \%$ in $1 \mathrm{~m}$ depth and high soil temperatures $\left(26^{\circ} \mathrm{C}\right.$ at the surface and $16^{\circ} \mathrm{C}$ in $2 \mathrm{~m}$ depth). In spring 2005 soil moisture increased from $14.7 \%$ at the surface to $22 \%$ in $2 \mathrm{~m}$ depth, but soil temperature was low as $8^{\circ} \mathrm{C}$.
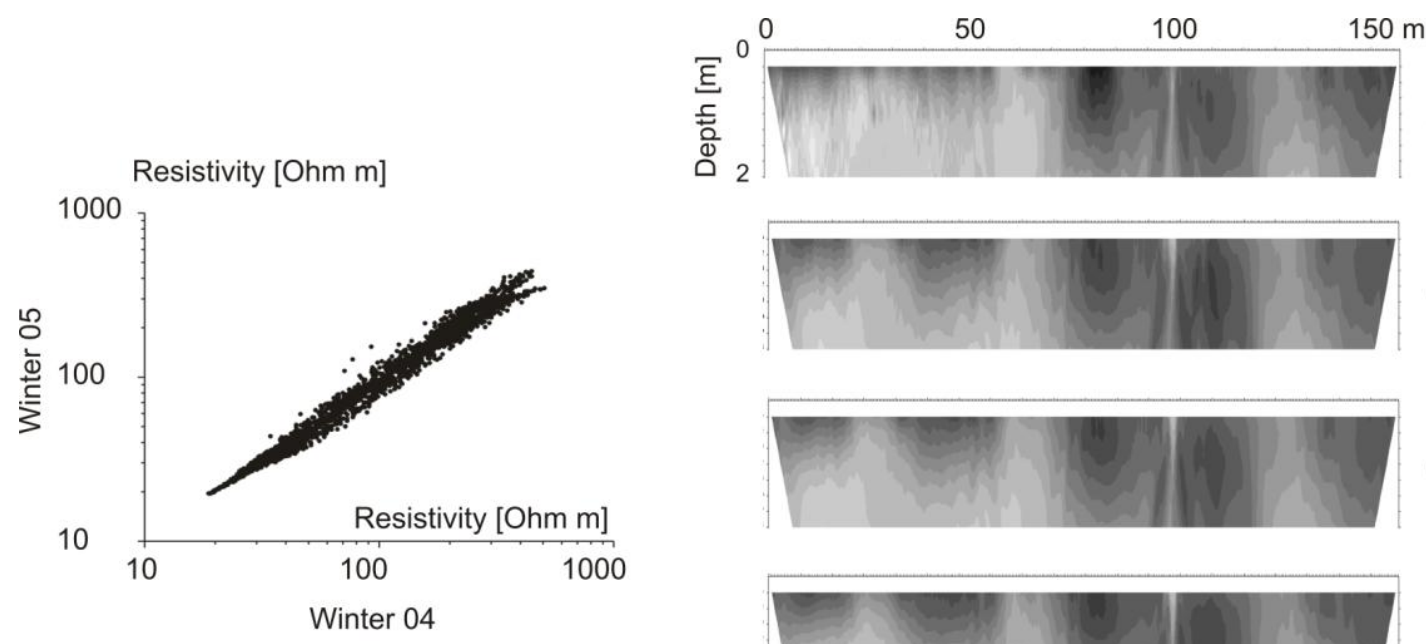

Summer 03

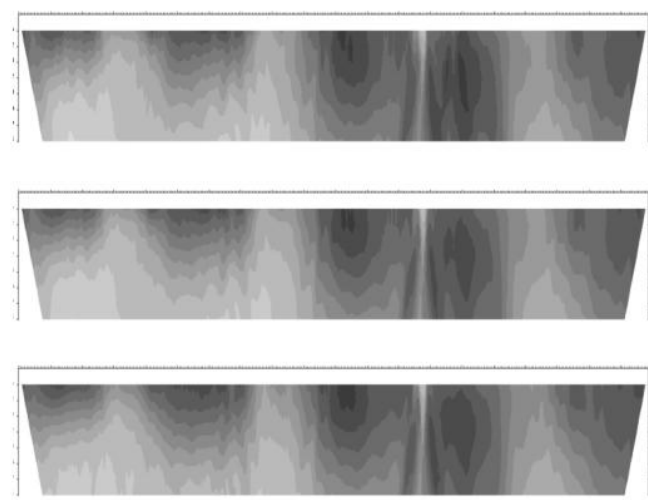

Winter 04

Winter 05

Resistivity [Ohm m]

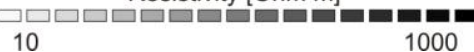

Spring 05

Fig. 6: Comparison of resistivity pseudosections measured with GeoTom at different dates 
Stability of ECa patterns (not the absolute values) over time was also observed by other authors (e.g. Sudduth et al., 2003). As pointed out by Schmidhalter, Zintel \& Neudecker 2003, clay content and water content are usually the most important factors causing spatial variation in EC maps under temperate conditions. While soil texture is quite stable over time, water content is variable. However, water content on mineral, non-hydromorphic soils largely depends on soil texture, namely on clay content. For mineral soils, deviations between water and clay content can only be introduced by wetting a short time after precipitation, variations of groundwater level, lateral water flow or diverging water uptake by crops. Obviously, these situations did not occur during our measurement on the test site or did not have a noticeable effect. Thus, distribution of soil water was predominantly governed by soil texture causing high stability of spatio-temporal patterns of EC.

\section{Positioning errors}

During data processing, special care was taken to account for positioning errors. The errors in positioning could originate from the accuracy of GPS due to the position and number of satellites, ambiguities, differential signal, interference, multipath effects etc. Horizontal dilution of precision for a typical dGPS is in the range of $2 \mathrm{~m}$. Also, a possible offset between the GPS antenna and the sensor should be considered. Both sources of positioning errors were relevant at our scale of investigation. For example, the offset between dGPS antenna and the center of the quadripole sensors of the Veris 3100 becomes clearly visible in Fig. 7. Fig. 7 shows the same profile made in both directions. Data of all instruments were analyzed and further corrected from positioning errors during the calculation of cross correlations with the GeoTom reference. This was done by automatically shifting profiles up to $2 \mathrm{~m}$ until $\tau$ was at maximum.

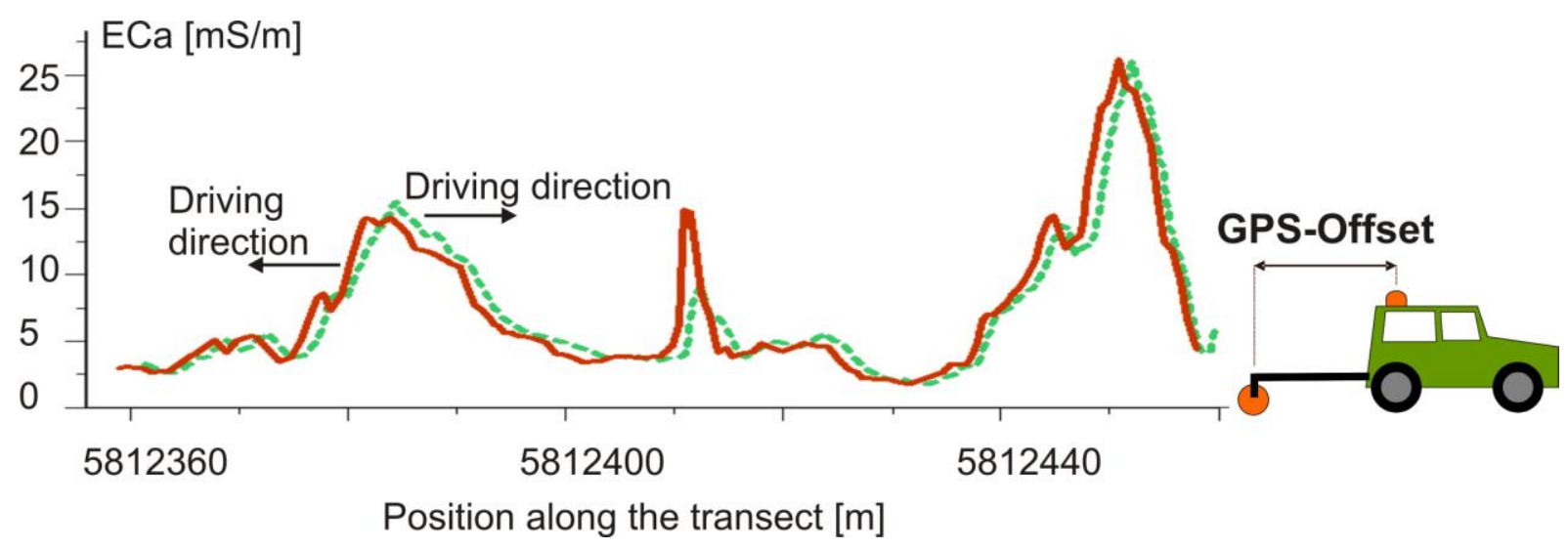

Fig. 7: Horizontal shift of measurements made in opposite directions due to GPS antenna offset

\section{D comparison between instruments over the transect}

Pseudosections along the transect derived from inversion of GeoTom measurements are shown in Fig. 6. In Fig. 8, raw data (ECa) from only four electrode spacing are presented. Conductivities show a general trend, decreasing from left to right. Dynamic range is from 1 to $75 \mathrm{mS} / \mathrm{m}$. Based on variography, different scales of lateral spatial variations were observed at ranges of approximately $10 \mathrm{~m}, 20 \mathrm{~m}$ and $50 \mathrm{~m}$. Additionally, very small scale variability of about $5 \mathrm{~m}$ was present at the very surface. Conductivities often increase with depth over the 
profile but the vertical stratification changes (Fig. 6). We can observe a strong layering in the left part of the profile whereas the vertical differentiation in the right part is smaller.

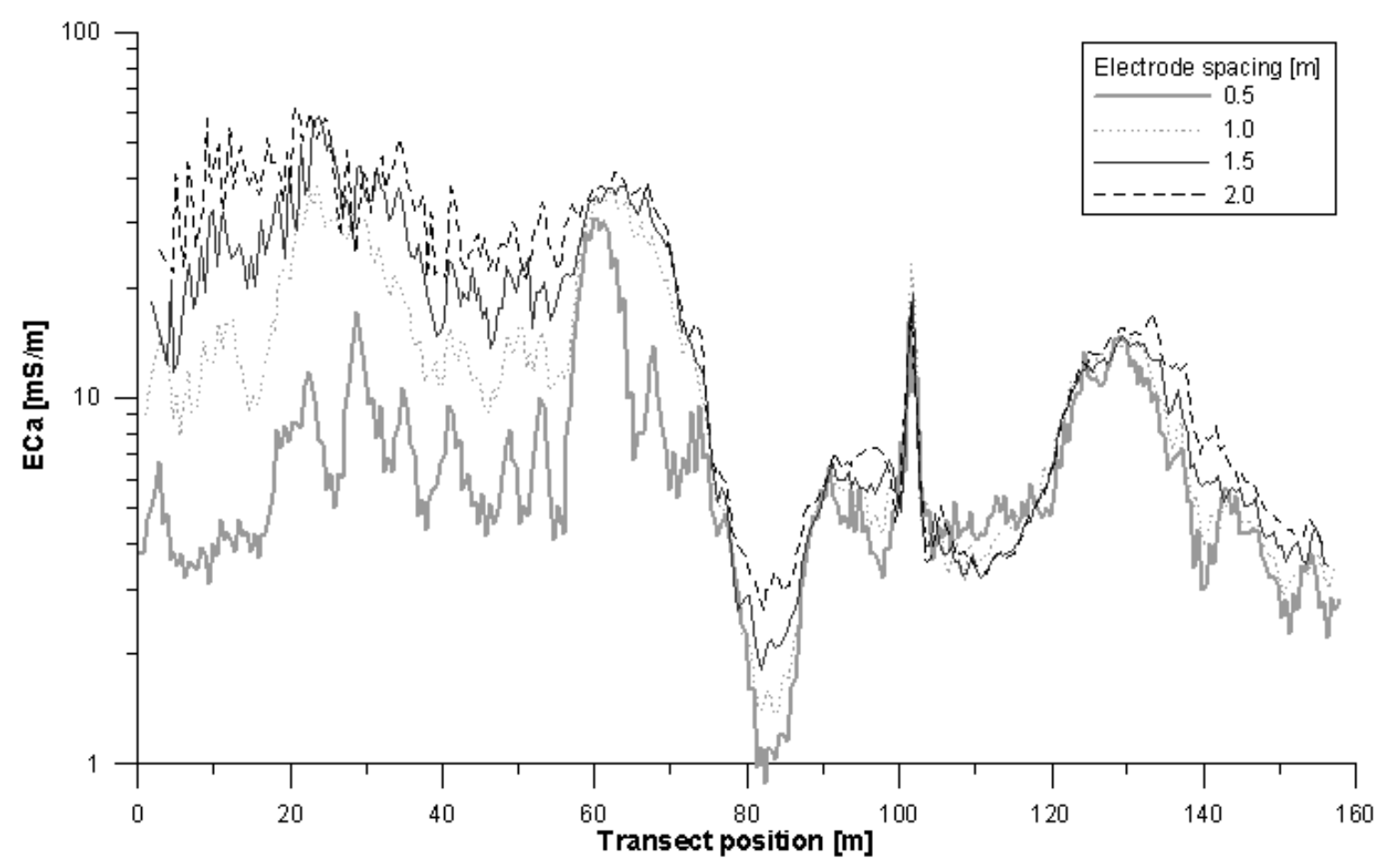

Fig. 8: Electrical conductivities measured by the GeoTom multi-electrode system in summer 2003

\section{Comparison of the reference methods}

In order to test the reliability of the GeoTom data, apparent conductivities were converted to true layer conductivities by 2D inversion with RES2DINV. These layer conductivities were compared with in-situ measurements by the ERM borehole probe. Fig. 9 shows inversion results together with some boreholes $\operatorname{logs}(1 \mathrm{~m}$ deep). We can see the good accordance of inverted conductivities and bore hole conductivities except for point 60 where a 3D effect is probably interfering. 


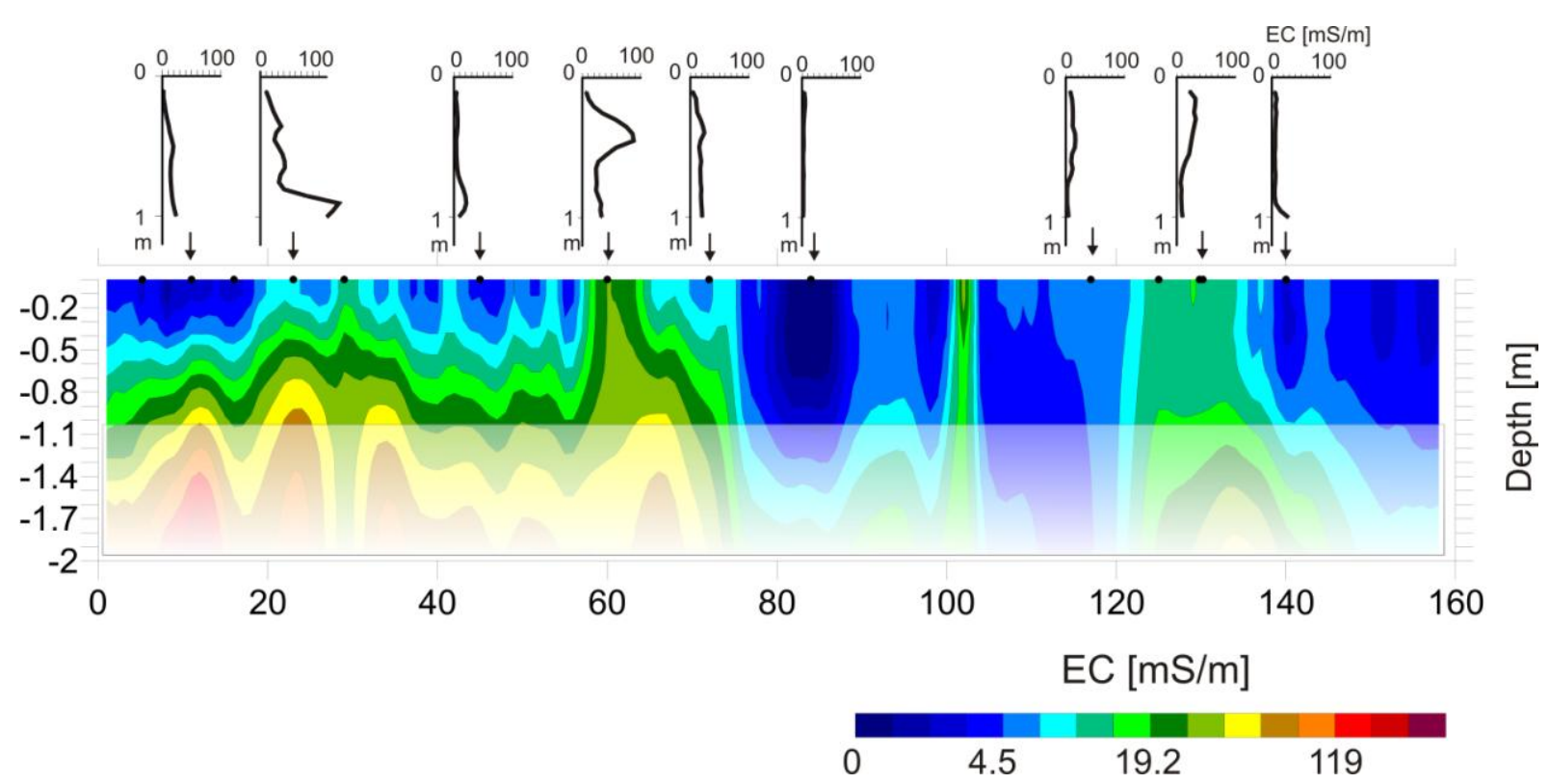

Fig. 9: GeoTom pseudosection (up to $2 \mathrm{~m}$ depth) and some logs of the direct push measurements (up to $1 \mathrm{~m}$ depth)

Fig. 10 summarizes the comparison at all 14 boreholes measured at two dates. At each date surface and in-situ data were collected simultaneously.

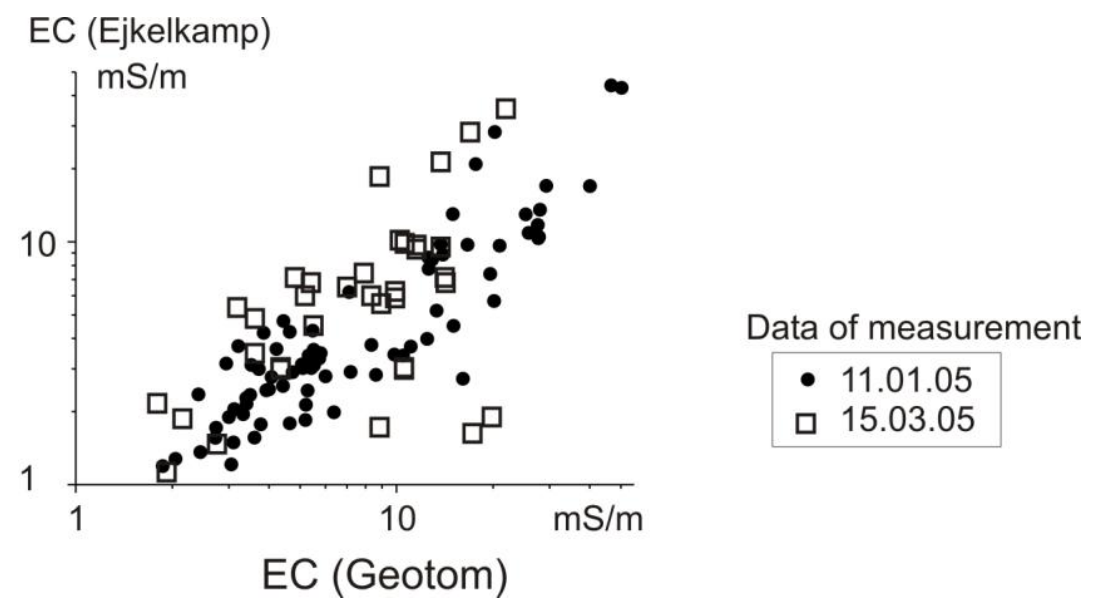

Fig. 10: Comparison of direct push measurements made by the ERM borehole probe and inverted EC-values measured from the surface by the GeoTom

\section{Mobile instruments}

The Veris 3100 was used twice all over the field. Unfortunately, during the first measurements in summer 2003 the operator of the instrument did not use additional weights to improve soil contact as recommended by the users manual. Because of the dry soil conditions, mapping results were rather noisy and showing several gaps. Measurements were repeated again in 'good' conditions in April 2004, when the soil moisture was higher. The imaged structures looked similar but the spatial density was much better in April 2004. For high resistive soils, the coupling between the electrodes and the soil is difficult because, either there was no soil contact or the Veris resistivimeter could not tolerate the high contact resistance (probably more than 50KOhm). 
Fig. 11 pictures the results obtained for the two Wenner configurations (Veris shallow ' $\mathrm{a}$ ' $=0.24$ and Veris deep ' $\mathrm{a}$ ' $=0.72 \mathrm{~m}$ ) compared to GeoTom data. We can see the good concordance of the data specially the Veris deep with the GeoTom ' $a$ ' $=0.5 \mathrm{~m}$. Some little discrepancies exist at the beginning of the profile, but this can be due to very short wavelength that cannot be resolved by the Veris system (integration of data before output and measurement every second).

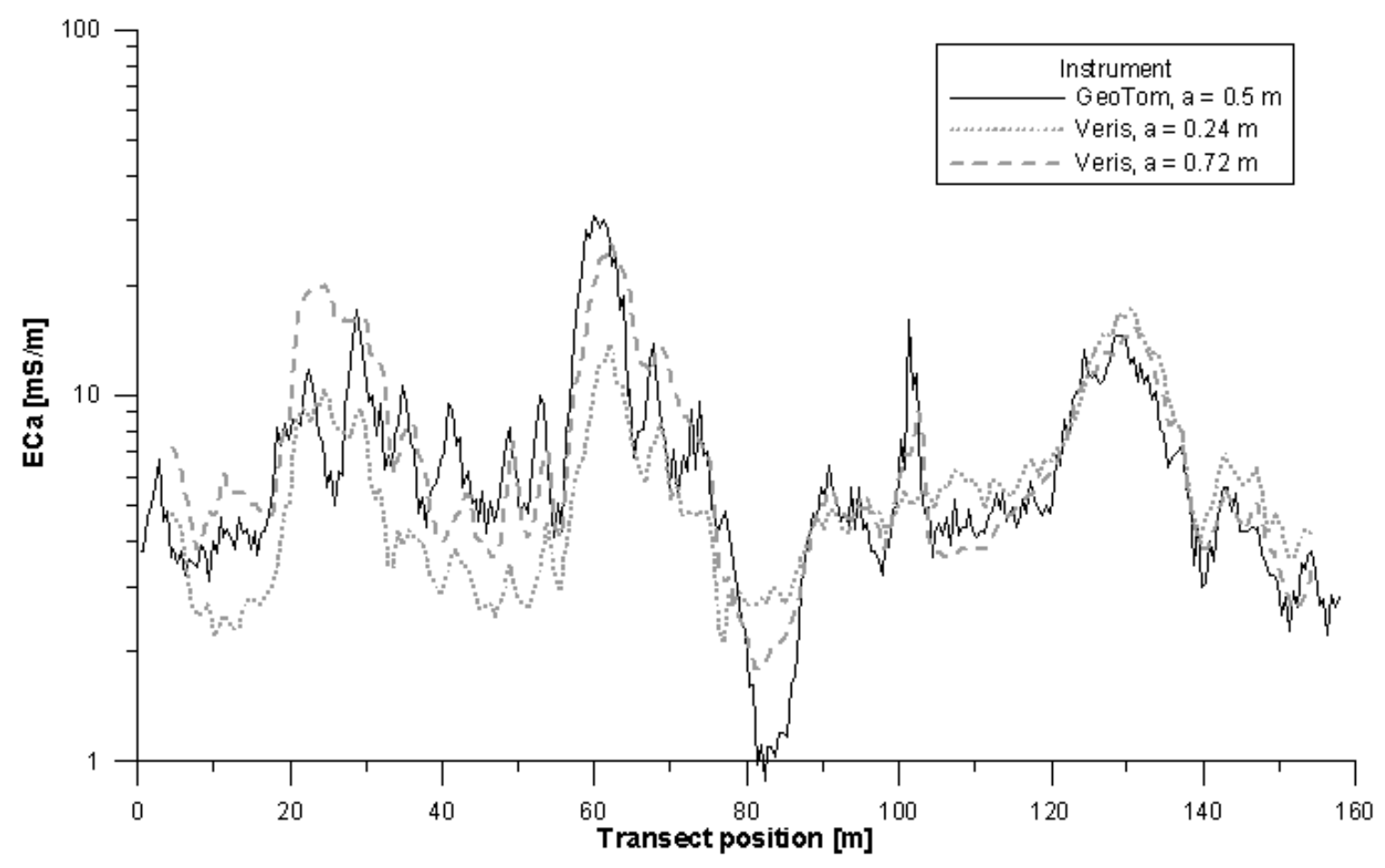

Fig. 11: Veris 3100 compared to GeoTom

The same processing was done for the ARP data (Fig. 12). This system measures with a very high frequency (time increment of $44 \mathrm{~ms}$ between single measurements) continuously the ER with three different quadripoles that enable three depths of investigation $0.5 \mathrm{~m}$ (channel 1), 1 $\mathrm{m}$ (channel 2) and $2 \mathrm{~m}$ (channel3). The data were acquired over the whole field in July 2003. Despite the very difficult conditions already quoted before, ARP data have shown a very good correlation with GeoTom data in the Wenner ' $\mathrm{a}$ ' $=0.5,1$ and $2 \mathrm{~m}$ inter-electrode configuration. The absolute values follow clearly most of the details of this transect. The ARP resistivimeter has a high tolerance to contact resistance. 


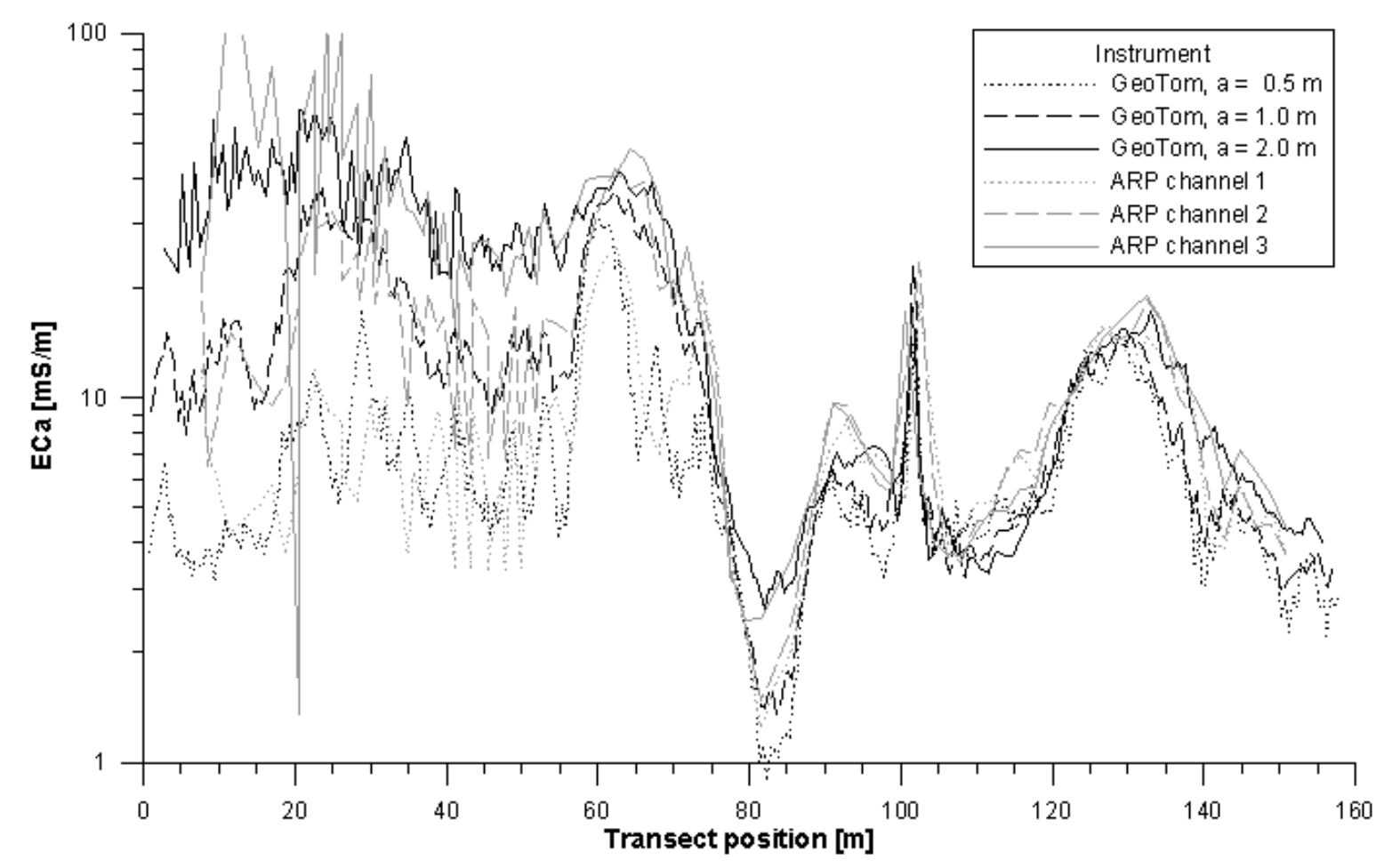

Fig. 12: ARP compared to GeoTom

EM38-DD data were acquired over the whole field in July 2003. Fig. 13 pictures the variations of EC measured by the EM38-DD (absolute calibration with EMI instruments is always difficult and amplitudes were arbitrary shifted). Conductivities measured in the vertical mode VCP (horizontal coils and vertical dipole) are higher than conductivities measured in the horizontal mode HCP (vertical coils, horizontal dipoles). This is in accordance with the higher depth of investigation in the VCP mode. Despite the fact that the amplitudes follow the general trend of transect, the dynamic is not the same as the one measured with GeoTom. Data seem also to be much smoothed. Finally at some places, some low conductivities anomalies do not seem to have any correspondence with GeoTom anomalies especially in VCP mode. For example at position 140 the anomaly should originate from a buried metal object. At position 100, a pipe is known to exist. Later on, measurements were made with a normal EM38. This time, geroreferencing was done with a tape measure. Results were very similar. As shown in Fig. 16, correlations with the GeoTom were nearly identical. 


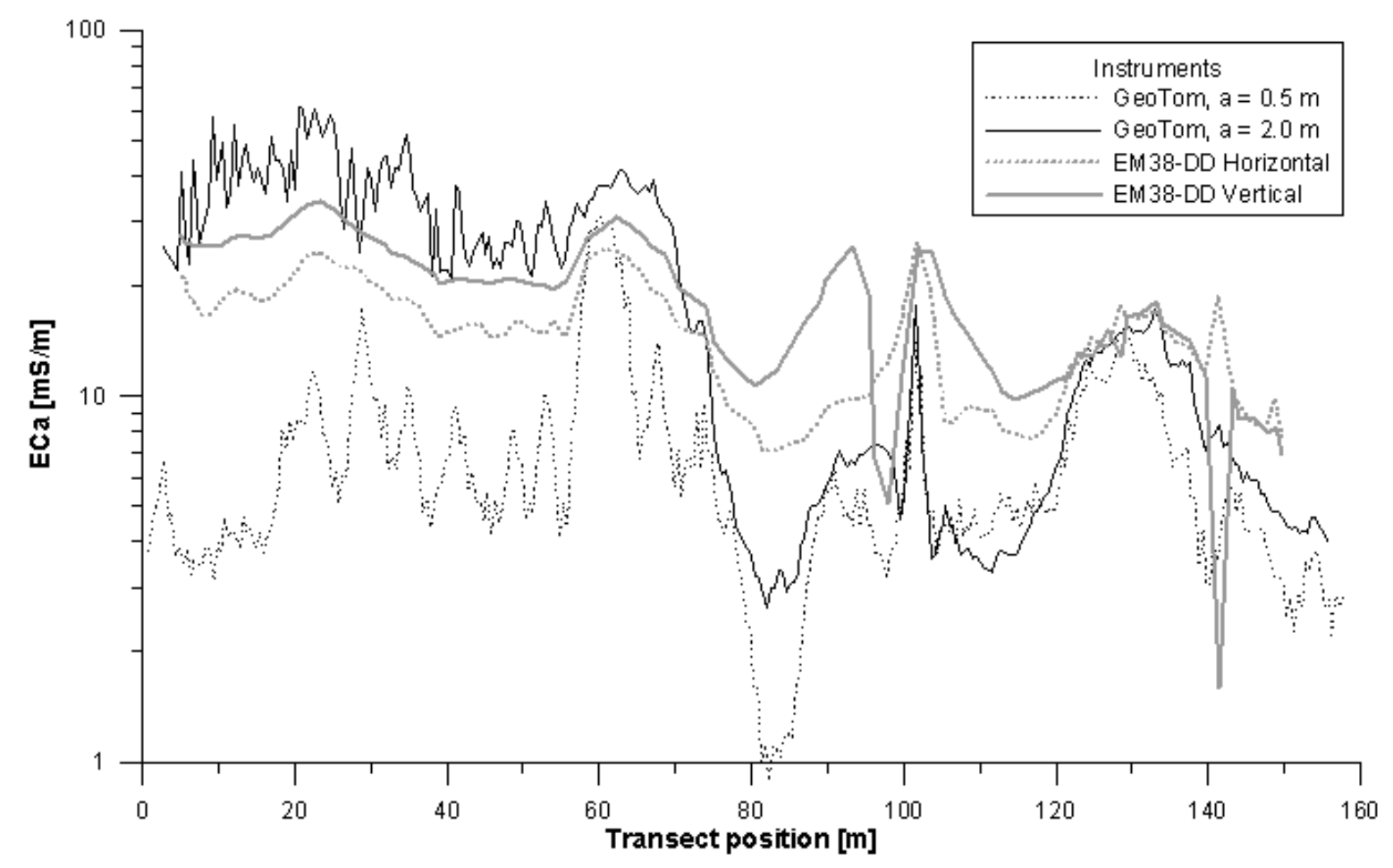

Fig. 13: EM38-DD compared to GeoTom

Transect was measured also in vertical and horizontal mode with an ordinary EM38 in July 2003. Data are much the same as the one obtained with EM38DD even if some more small heterogeneities appear because of a dense sampling interval along transect. Calibration tests were carried out to study the influence on absolute values as well as on differentiation along the profile. The level of absolute values is strongly influenced by the calibration at the beginning. The variation along transect is more or less independent on this.

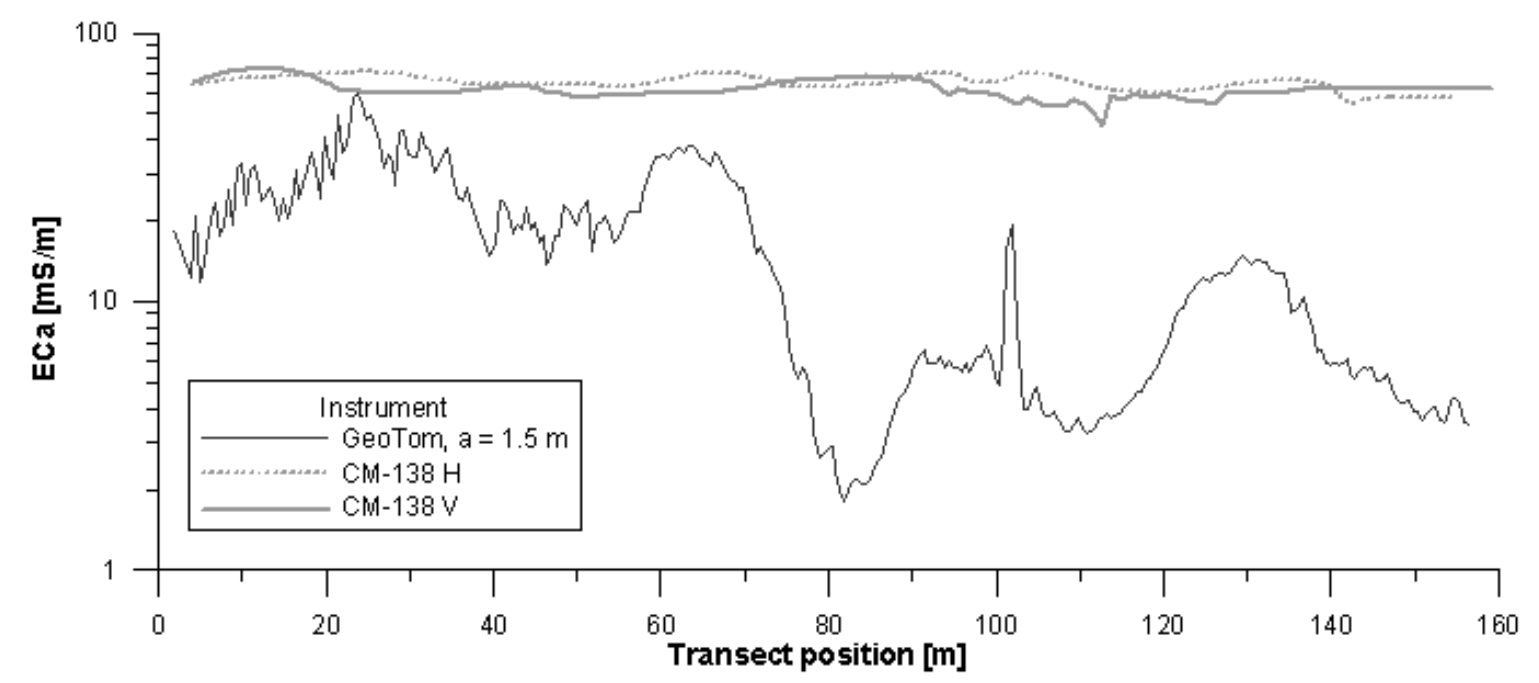

Fig. 14: CM-138 compared to GeoTom

The performance of the CM-138 was rather poor. As one can derive from Fig. 14, absolute values of the CM-138 were shifted and dynamics was low. It is hard to recognize any correspondence between readings of the CM-138 and the GeoTom in this figure, but correlation analysis indicated some accordance between the vertical mode of the CM-138 and GeoTom at 'a' $=1.5 \mathrm{~m}$ (Fig. 16). Data produced in the horizontal mode turned out to be 
completely useless. In fact, data shown in Fig. 14 and Fig. 16 were the best results from four runs with the $\mathrm{CM}-138$ in the $\mathrm{H}$ and $\mathrm{V}$ mode, respectively. We assume that the low accuracy of the CM-138 can be explained by its sensitivity to ambient temperature and the erratic jumps observed during our time stability tests.

Measurements with the OhmMapper were done in October 2005. The system was dragged by hand. Because the dipole-dipole-array of the OhmMapper could be modified easily, selecting different line electrodes and arbitrary separations distances between the dipoles, we used seven configurations to obtain data from different depths. These data, sampled every $0.5 \mathrm{~m}$ along the transect, were inverted with RES2INV. The upper part of Fig. 15 presents the pseudosection obtained with the GeoTom (Wenner array), in the lower part we can see the inversion results from the OhmMapper.
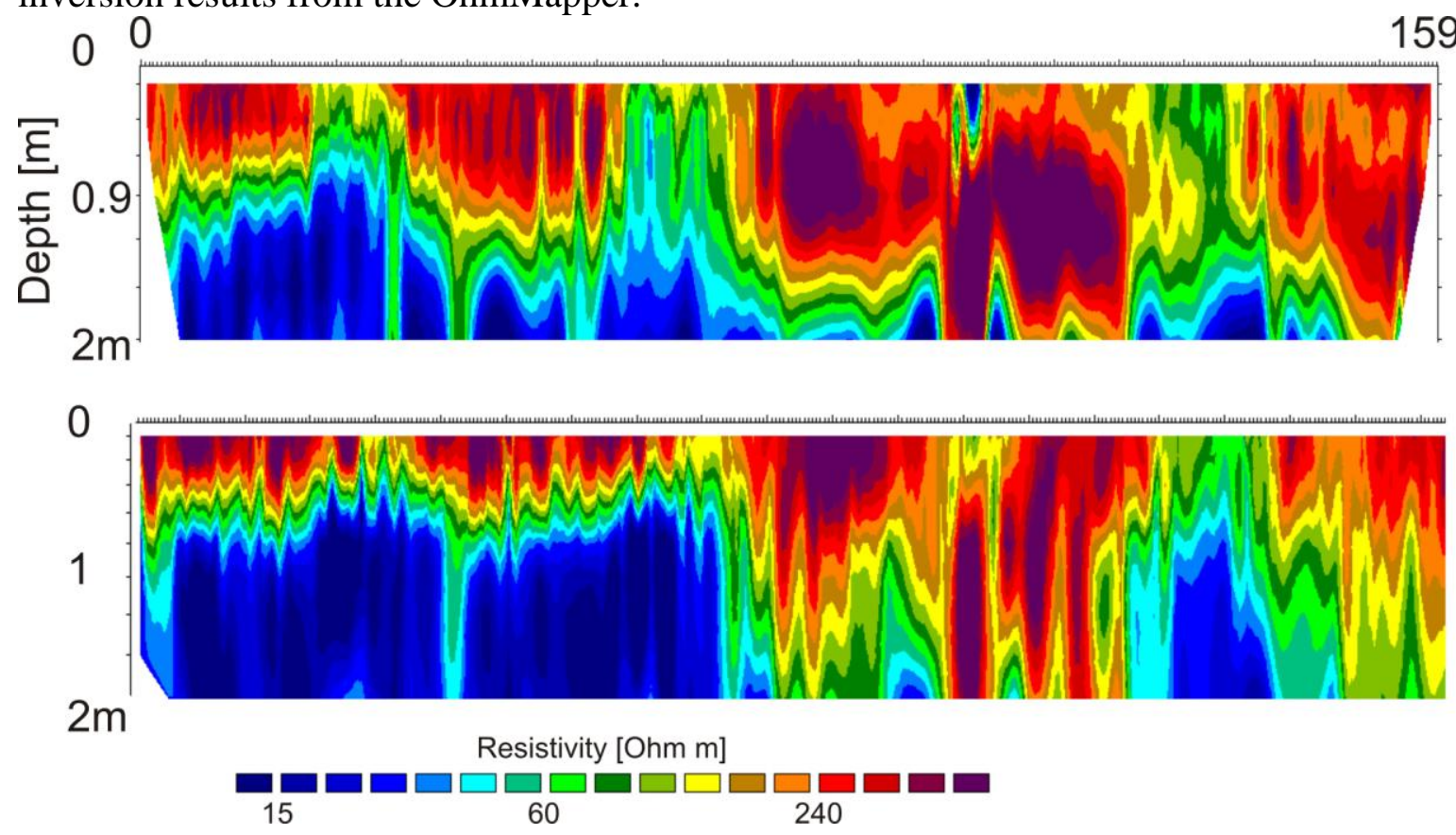

Fig. 15: OhmMapper compared to GeoTom. Inverted resistivity sections (above: Wenner-Array GeoTom, below: Dipole-Dipole-Array OhmMapper)

Resistivity sections in Fig. 15 show similar structures at the same absolute values. To explain differences of resistivity patterns in the pseudosection we can think of three reasons: a) Because of the minimum dipole length of $5 \mathrm{~m}$ available in the experiment, the OhmMapper was not able to focus on very shallow layers (see correlations in Fig. 16). b) In general, measurements with the $5 \mathrm{~m}$ dipole were noisier than with the $10 \mathrm{~m}$ dipole. This is due to the fact that it is more difficult to maintain a stable soil contact with the smaller cables. c) According to Roy \& Apparao 1971, the dipole-dipole configuration has a lower vertical resolution than the Wenner configuration; this can cause poorer inversion results.

It should be mentioned that the OhmMapper results presented here are only valid for dry sandy soils or other resistive grounds. They do not apply for conductive soils (Gebbers \& Lück 2007, Doll et al. 2001).

\section{Summary of cross correlations over the transect}


The comparison of different dataset with GeoTom data taken as a reference gives an idea of the depth of investigation as well as of the horizontal resolution. If there is no vertical stratification then the coefficients should be similar within each dataset.

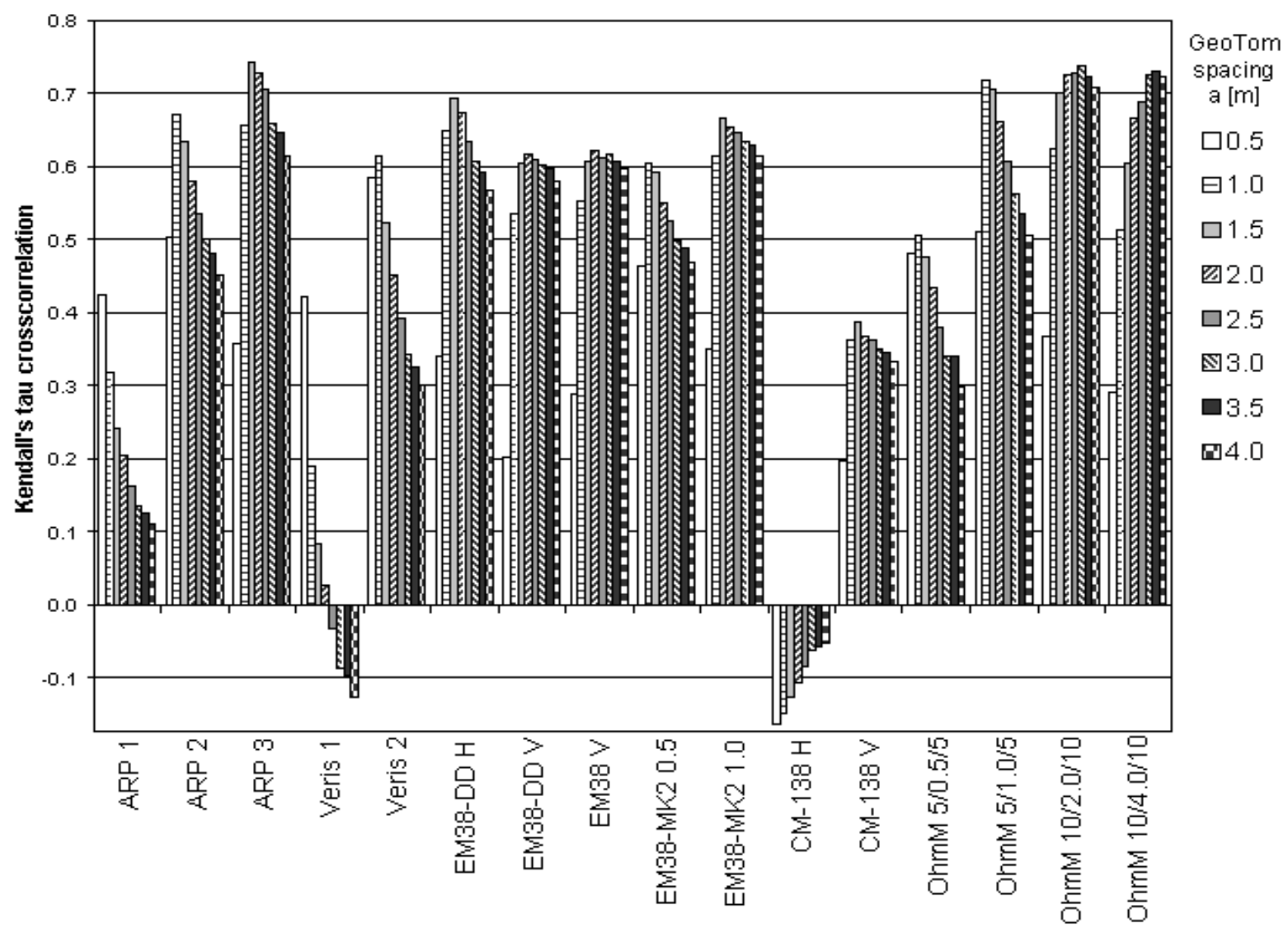

Fig. 16: Kendall coefficient of correlation $\tau$ between GeoTom EC values for different electrode spacings and other instruments output (for the OhmMapper, only four configurations are shown)

Fig. 16 displays all $\tau$ coefficients computed between the different measurements of different Wenner configurations (GeoTom) and outputs of the tested instruments. These coefficients are generally lower for the smallest depth (' $\mathrm{a}$ ' $=0.5 \mathrm{~m})$ with the only exceptions of Veris shallow and ARP Channel1. Both instruments/channels outputs are primarily related to variations in a very shallow layer, as captured by a Wenner array of ' $\mathrm{a}$ ' $=0.5 \mathrm{~m}$. This result does not mean that these 2 instruments have the same depth of exploration. If we had the possibility of having GeoTom data with a smaller ' $a$ ', the correlation would be higher between Veris shallow and these GeoTom data. Moreover, the rate of decrease of $\tau$ with GeoTom ' $a$ ' is clearly higher with Veris data than with ARP data. For Veris deep, the rate of decrease is lower and comparable with ARP Channel1. These two points were predicted by the depth sensitivity curves. The lower coefficients for small ' $a$ ' do not prove that the performance of instruments is worse. It is just a consequence of small-scale variability (less than $1 \mathrm{~m}$ ) in the data. This variability is smoothed by configurations with a larger ' $\mathrm{a}$ ', which were increasingly integrating apparent resistivity over a bigger soil volume. It is interesting to notice that despite the fact that measurements with ARP were acquired in very dry conditions June 2003) with high contact resistance, the highest $\tau$ coefficients for the 3 depth: 0.5, 1 and $2 \mathrm{~m}$ are quite high. It is probable than the $\tau$ coefficients would have been even higher if ARP measurements were taken at the same time than the Veris data (May 2004). 
For EM38 data, we find that depth of penetration in VCP is greater to HCP and the rate of decrease of $\tau$ with ' $a$ ' is also very slow. It is interesting to notice that the coefficient of 0.62 is identical for EM38-DD and EM38 in vertical mode for $\mathrm{a}=2 \mathrm{~m}$.

Correlations with the EM38-MK2 proved that this new instrument is capable to detect variation in shallower layers than the EM38.

The OhmMapper shows a very good performance over all depths. Only the very shallow layer, which was equivalent to 'a' of $0.5 \mathrm{~m}$, was not sufficiently captured by the electrode configurations we used. We assume that the good results were partly due to the resistive soils of the test site and partly due to fact that we dragged the instrument by hand. On other sites, we have dragged the OhmMapper at higher speeds by a vehicle, which caused a considerable noise in the data.

\section{D case: comparison over the whole test area}

Data obtained with EM38-DD, EM38, Veris and ARP were interpolated using a triangulated irregular network (TIN) operator and displayed with the same scale (Fig. 17).

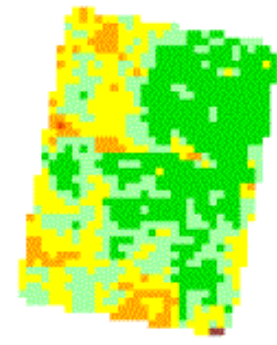

ARP 1

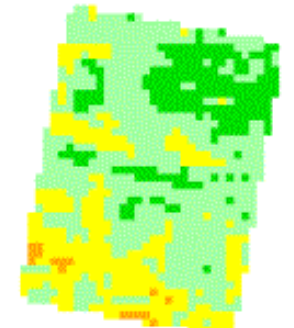

Veris shallow

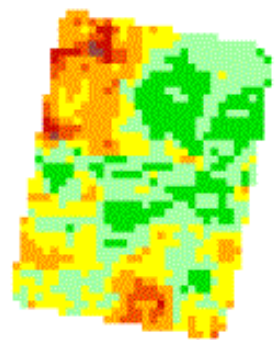

ARP 2

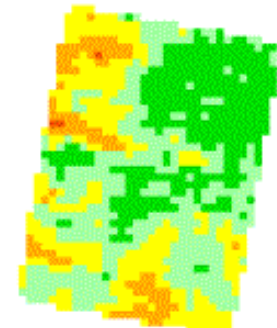

Veris deep

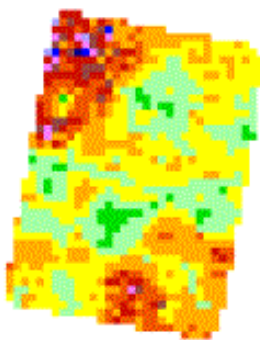

ARP 3

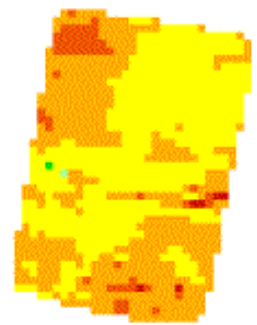

EM38-DD H

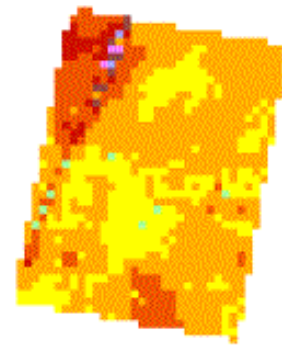

EM38 V

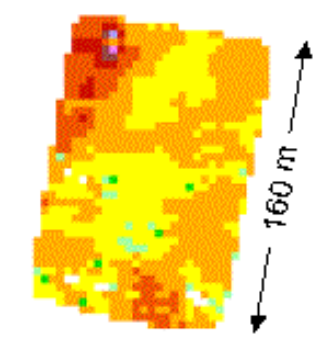

EM38-DD V

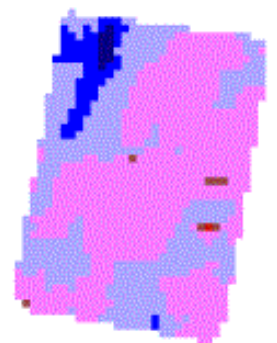

CM-138 V

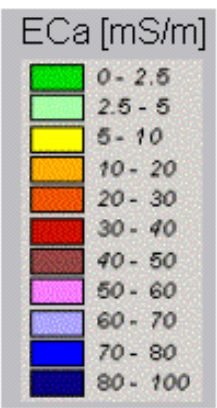

Fig. 17: EC maps for the test area made by five different instruments

As already noticed, the EM38-DD VCP and EM38 VCP maps are quite the same. Veris1 (Veris shallow) is similar to ARP channel1. All the results which were already quoted during the intercorrelation process on the transect seem to be valid for the whole test area.

\section{Conclusions}

From the practical point of view of field application in agriculture, we have recognized three sources of errors: error in positioning, instrumental errors and data processing errors.

- The errors in positioning could originate from the accuracy of GPS and antenna offset. The antenna offset can be easily corrected. GPS errors of about $2 \mathrm{~m}$ do not substantially reduce quality of map for PA with a typical resolution of 10 by $10 \mathrm{~m}$. 
- The errors in instrumentation could result from a bad calibration (CM-138, EM38), a malfunctioning (high contact resistance with the Veris 3100), disturbances coming from the near environment (temperature effects, electromagnetic distortions, vibrations, presence of scattered metal objects) or other, unknown reasons (erratic drifts with CM-138, small random errors, inherent in any measurement).

- Finally regarding data processing, we observed differences between instruments related to sampling rate and/or resolution, processing delay - or latency -, which means that output of some instruments is buffered and smoothed. However, these effects are not relevant for the spatial resolution needed in PA.

The most important instrument errors are drifts. The can definitely affect map quality to an amount which is considerable for PA.

However, an even more important problem concerns the appropriate usage of the instruments. Depth sensitivity has to be regarded when interpreting mapping results. The most important soil layers are within $60 \mathrm{~cm}$ depth, because here we can find most of the crop roots. The ARP, the Veris 3100, EM38-MK2 and the OhmMapper were able to investigate these very shallow layers. The EM38, which is the most popular sensor in PA, senses too deep and is not the appropriate instrument to investigate the major rooting zone.

The advantages of using EMI methods were found to be the low weight and the small dimensions of the instruments. The disadvantage of the EMI methods is its sensitivity to ambient noise. In the worst case, as with the CM-138, mapping results become nearly useless. The CM-138 and the EM38, EM38-DD are scanning a large soil volume and they are more sensitive to deeper soil layers, less relevant for plant growth. With the new EM38-MK2, Geonics introduces an EMI sensor, which is focused on more shallow layers probably more relevant for PA.

The drawbacks of using GCR methods were found to be in the high weight of the instruments (> $400 \mathrm{~kg}$ ) and the large dimensions compared to EMI instruments. Problems may also appear for instruments like Veris 3100 that could not withstand high contact resistances and/or low soil resistivities. Compared to Veris, the ARP system has performed slightly better in this experiment showing the higher coefficient of spatial correlation with data obtained with a multi electrode system taken as a reference, even if data were collected at the worse period in terms of contact resistance. These coefficients would probably be higher if ARP data were taken at the same time than the Veris data. The very quick response time of this instrument makes data collection at high speed possible with no spatial lag and enables the mapping of short wavelength anomalies. Contrary to the ARP, the handling of the Veris is much simpler. The Veris on-board computer integrates the resistivimeter and needs just four buttons to be operated. Unlike the ARP, the Veris selects the injected current automatically and data are integrated over a $1 \mathrm{sec}$ interval in real time. Of course, the more sophisticated ARP system provides more options to tackle difficult conditions and the usage of such system requires a more trained operator. In general, ER is less sensitive to ambient noise and produce absolute values.

The capacitive coupled OhmMapper is a new type of instrument, which has rarely been used in PA. One of the principal advantages of the OhmMapper is that by capacitively coupling with the ground, the system can collect resistivity data in areas where the near surface is extremely resistive. Conversely, in regions where the near surface is extremely conductive, the capacitive coupling of the OhmMapper provides little signal penetration and the resulting data were noisy (Doll et al. 2001). The line electrodes arrange in a dipole-dipole array provide high flexibility in selecting depth of investigation. However, line electrodes are another major drawback of the system with respect to handling in practice. When attached to an ATV, the 
line electrodes tend to rip off because they easily get hooked up on obstacles. Turning in the headlands is difficult and data become very noisy. Because of these handling problems and the poor performances on conductive soils, the OhmMapper as it is now will probably not become very popular in PA.

\section{References}

Allred, B., Ehsani, M.R., Saraswat, D. 2006. Comparison of electromagnetic induction, capacitively-coupled resistivity, and galvanic contact resistivity methods for soil electrical conductivity measurement. Applied Engineering in Agriculture 22 (2), 215-230

Anderson-Cook, C.M., Alley, M.M., Roygard, J.K.F., Khosla, R., Noble, R.B., Doolittle, J.A. 2002. Differentiating soil types using electrical conductivity and yield maps. Soil Science Society of America Journal 66, 1562-1570

Baker, G.S. 2003. Electrical Resistivity 2D Inversion Tutorial. UB Geophysics Supplemental Report 2003-S01. Department of Geology, University of Buffalo

Bobert, J., Schmidt, F., Gebbers, R., Selige, T., Schmidthalter, U. Estimating soil moisture distribution for crop management practices with capacitance probes, EM-38 and digital terrain analysis. In: Proceedings of the Third Conference on Precision Agriculture, edited by Grenier, G. ans Blackmore, S.(Agro Montpellier, Ecole Nationale Supérieure Agronomique, France), 349-354

Cockx, L., Van Meirvenne, M., Hofman, G. 2005. Characterization of nitrogen dynamics in a pasture soil by electromagnetic induction. Biology and Fertility of Soil 42, 24-30

Dabas M., Hesse A., Jolivet A. 1989. In : Prospection électrique de sub-surface automatisée, éd.CIRA, Centre Interdisciplinaire de Recherches Archéologiques, Bruxelles, pp. 73-81.

Dabas M., Hesse A., Jolivet A., Tabbagh A., Ducomet G., 1989 . Intérêt de la cartographie de la résistivité électrique pour la connaissance du sol à grande échelle. Science du Sol, 27, 1, 65-68.

Dabas, M., Décriaud, J.P., Ducomet, G., Hesse, A., Mounir, A., Tabbagh A. 1994. Continuous recording of resistivity with towed arrays for systematic mapping of buried structures at shallow depth. Revue d'Archéométrie, 18, 13-19

Dabas, M., Tabbagh, J., Tabbagh, J. 1994. 3D-inversion in subsurface electrical surveying - I. Theory. Geophysical Journal International, 119, 975-90

Dabas, M., Tabbagh, A. 2002. A Comparison of EMI and DC methods used in soil mapping - theoretical considerations for Precision Agriculture. In: Precision Agriculture, edited by J. Stafford and A. Werner, Wageningen Academic Publishers, 121-129

Dabas M., Gebbers R., Domsch H., 2004. A comparison of different sensors for soil mapping: the ATB case study, paper presented at $7^{\text {th }}$ Int. Conf. On Presion Agricuture, Minneapolis, 2528 Juillet 2004, in press. 
de Jong, E., Ballantyne, A.K., Cameron, D.R., Read, D.W.L. 1979. Measurement of apparent electrical conductivity of soils by an electromagnetic induction probe to aid salinity surveys. Soil Science Society of America Journal 43, 810-812.

Doll, W.E., Gamey, T.J., Nyquist, J.E., Mandell, W., Groom, D., Rohdewald, S. 2001. Evaluation of new geophysical tools for investigation of a landfill, Camp Roberts, California. In Proceedings, 2001 Symposium on the Application of Geophysics to Engineering and Environmental Problems. (SAGEEP), 4-7 March 2001, Denver, Colorado

Domsch, H., Giebel, A. 2004. Estimation of soil textural features from soil electrical conductivity recorded using the EM38. Precision Agriculture 3, 389-409

Gebbers, R., Lück, E. 2007. Der OhmMapper - Geoelektrik-Kartierung mit kapazitiver Ankopplung. (The OhmMapper - geoelectrical mapping based on capacitive coupling) Landtechnik 2, $82 \ldots 83$

Jung, W.K., Kitchen, N.R., Sudduth, K.A., Kremer, R.J., Motavalli, P.P. 2005. Relationship of apparent conductivity to claypan soil properties. Soil Science Society of America Journal $69,883-892$

Kachanoski, R.G., Gregorich, E.G., Van Wesenbeck, J. 1988. Estimating spatial variations of soil water content using noncontacting electromagnetic induction methods. Canadian Journal of Soil Science 68, 715-722.

Kerry, R., Oliver, M. 2003. Variograms of ancillary data to aid sampling for soil surveys. Precision Agriculture 4, 261-278

King, J.A., Dampney, P.M.R., Lark, R.M., Wheeler, H.C., Bradley, R.I, Mayr, T.R. 2005. Mapping potential crop management zones within fields: Use of yield-map series and patterns of soil physical properties identified by electromagnetic induction. Precision Agriculture 6, $167-181$

Korsaeth, A. 2005. Soil apparent electrical conductivity (ECa) as a means of monitoring changes in soil inorganic $\mathrm{N}$ on heterogeneous morainic soils in SE Norway during two growing seasons. Nutrient Cycling in Agroecosystems 72, 213-227

Lesch, S.M., Corwin, D.L, Robinson, D.A. 2005: Apparent soil electrical conductivity mapping as an agricultural management tool in arid zone soils. Computers and Electronics in Agriculture 46, 351-378

Lück, E., Eisenreich, M. Electrical conductivity mapping for precision agriculture. In: Proceedings of the Third Conference on Precision Agriculture, edited by Grenier, G. ans Blackmore, S.(Agro Montpellier, Ecole Nationale Supérieure Agronomique, France), 425-429

McNeill, J. D., 1980. Electromagnetic terrain conductivity measurements at low induction numbers, Geonics Technical Note TN-6.

Nabighian, M.N., 1987. Electromagnetic methods in applied geophysics. Society of Exploration Geophysicists, Tulsa, Oklahoma 
Panissod, C., Dabas, M., Jolivet, A., Tabbagh, A. 1997. A novel mobile multipole system (MUCEP) for shallow (0-3m) geoelectrical investigation : the 'Vol-de-canards' array. Geophysical prospecting, 45, 983-1002.

Panissod, C., Dabas, M., Hesse, A., Jolivet, A., Tabbagh, J., Tabbagh, A. 1998. Recent developments in shallow-depth electrical and electrostatic prospecting using mobile arrays, Geophysics, 63, 5, 1542-1550.

Reedy, R.C., Scanlon, B.R. 2003. Soil water content monitoring using electromagnetic induction. Journal of Geotechnical and Geoenvironmental Engineering, Nov. 2003, 10281039

Robert, P., 2000. L'agriculture de précision : les verrous technologiques liés à la technologie et à la gestion agronomique. In : Agriculture de précision, Actes du colloque des 29 et 30 Mai 2000, ENESAD, Educagri eds., Dijon, 11-29

Schmidhalter, U., Zintel, A., Neudecker E. 2003. Calibration of electromagnetic induction measurements to survey the spatial variability of soils. In: Proceedings of the Third Conference on Precision Agriculture, edited by Grenier, G. ans Blackmore, S.(Agro Montpellier, Ecole Nationale Supérieure Agronomique, France), 479-484

Siegel S. 1985. Nichtparametrische statistische Methoden. Fachbuchhandlung fuer Psychologie, Frankfurt a. M., Germany. (German translation of Siegel, S. 1956. Nonparametric Statistics for the Behavioral Sciences. McGraw-Hill. New York.)

Sudduth, K.A., Drummond, S.T., Kitchen, N.R. 2001. Accuracy issues in electromagnetic induction sensing of soil electrical conductivity for precision agriculture. Computers and Electronics in Agriculture 31, 239-264.

Sudduth, K.A., Kitchen, N.R., Bollero, G.A., Bullock, D.G., Wiebold, W.J. 2003. Comparison of electromagnetic induction and direct sensing of soil electrical conductivity. Agronomy Journal 95, 472-482

Sudduth, K.A., Kitchen, N.R., Wiebold, W.J., Batchelor, W.D., Bollero, G.A., Bullock, D.G., Clay, D.E., Palm, H.L., Poerce, F.J., Schuler, R.T., Thele, K.D. 2005. Relating apparent electrical conductivity to soil properties across the north-central USA. Computers and Electronics in Agriculture 46, 263-283

Tarr, A.B., Moor, K.J, Burras, C.L., Bullock, D.G., Dixon, P.M. 2005. Improving map accuracy of soil variables using soil electrical conductivity as a covariate. Precision Agriculture 6, 255-270

Roy, A., Apparao, A. 1971. Depth of investigation in direct current methods. Geophysics, Vol. 36, No. 5, 943-959

Triantafilis, J., Laslett, G.M., McBratney, A.B. 2000. Calibrating an electromagnetic instrument to measure salinity in soil under irrigated cotton. Soil Science Society of America Journal 64, 1009-1017 